exact. Les derniers chapitres traitent de la guerre francoallemande, de la campagne sud-africaine, enfin des derniers conflits armés, de la guerre russo-japonaise jusqu'à celle des Balkans qu'il ne fait d'ailleurs guère qu'indiquer. Enfin il expose en quelques pages l'organisation actuelle, en 1913, du service de l'assistance volontaire en Grande-Bretagne.

Cette histoire populaire, succincte mais complète de tout le mouvement de charité à travers le monde en faveur des malades et des blessés, depuis ses balbutiements antiques jusqu'à son perfectionnement moderne, n'a sagement pas de prétention à l'originalité, mais telle qu'elle est, illustrée de planches, elle a son utilité et sa valeur, et il faut remercier l'auteur de l'avoir écrite.

\title{
GRÈCE
}

\section{Décès de m. Jean Valaoritis, président de la Croix-Rouge hellénique.}

Au moment de mettre sous presse nous recevons la triste nouvelle que nous communique la lettre suivante :

"Messieurs,

"Le Comité de la Croix-Rouge hellénique a l'honneur de vous faire part de la perte cruelle qu'il vient d'éprouver en la personne de son rəgretté Président, M. Jean Valaoritis, gouverneur de la banque nationale de Grèce, décédé le 16-29 mars courant.

"Athènes, le 18-31 mars 1914.

«Pour la Croix-Rouge hellénique :

"Le Secrétaire général,

«B. Patrikios.

Le Vice-Président, N.-G. Makkas." "

Nous réitérons ici au Comité d'Athènes, nos sincères 
condoléances pour la grande perte qu'il fait en la personne de son distingué Président, et nous réservons de revenir ultérieurement sur l'utile carrière du défunt.

\section{Loi du 21 janvier 1914 sur la protection de l'emblême et du nom de la Croix-Rouge}

Artigle premier. - Seule la Croix-Rouge hellénique (Société de secours aux blessés pendant la guerre) a le droit, en dehors de l'intendance sanitaire de l'Etat, de se servir de l'emblème de la Croix-Rouge sur fond blanc avec les mots Grorx-Rouge comme nom ou pour la désignation de son activité.

Ár. 2. - Quiconque, sans avoir droit à l'emploi de l'emblème de la Croix-Rouge sur fond blanc ou des mots "Croix-Rouge " aura appliqué ces mots ou cet emblème ou des mots analogues, pouvant prêter à confusion, sur les marchandises ou sur leur emballage, ou aura vendu, mis en vente ou en circulation de telles marchandises, ou aura employé indûment de quelque autre manière cet emblème ou ces mots, sera puni d'une amende jusqu'à 500 drachmes, ou d'emprisonnement jusqu'à un mois, ou de ces deux peines.

Ces peines pourront être élevées jusqu'au double, en cas de récidive, si trois années ne se sont pas écoulées depuis la dernière condamnation, passée en force de chose jugée, pour infraction à la présente loi.

ART. 3. - Les produits et emballages en contravention à la présente loi seront saisis par l'autorité compétente pénale. Même en cas d'acquittement, le tribunal correctionnel ordonnera la destruction des signes illégaux. Une fois les signes détruits, les produits saisis seront restitués à leur propriétaire contre paiement, entre les mains du greffier du tribunal, des frais de destruction, àinsi que des frais judiciaires et de l'amende.

En cas de non paiement de la part da propriétaire entre 